\title{
Romantic Relationship Status and Gender Differences in Sun Tanning Attitudes and Behaviors of U.S. College Students
}

\author{
Terry F. Pettijohn $\mathrm{II}^{1}$, Terry F. Pettijohn ${ }^{2}$, Alexandra G. Gilbert ${ }^{1}$ \\ ${ }^{1}$ Department of Psychology, Coastal Carolina University, Conway, South Carolina, USA; \\ ${ }^{2}$ Department of Psychology, the Ohio State University-Marion, Marion, Ohio, USA. \\ Email: pettijohn@coastal.edu \\ Received November $13^{\text {th }}, 2010$; revised January $25^{\text {th }}, 2011$; accepted February $10^{\text {th }}, 2011$.
}

\begin{abstract}
Male and female college students $(n=353)$ involved in varying degrees of romantic relationships responded to a questionnaire investigating sun tanning attitudes and behaviors. Females were predicted to engage in sun tanning more frequently and have more positive attitudes about sun tanning than males. Those students who were dating were also predicted to engage in more sun tanning behaviors and have more positive attitudes regarding tanning compared to students who were not dating, in committed romantic relationships, or married. Results supported these predictions overall. Females, and college students who were dating, engaged in more risky sun tanning behaviors and are therefore especially at risk for health related consequences of sun tanning.
\end{abstract}

Keywords: Sun Tanning, Gender Differences, Romantic Relationships, Skin Cancer

\section{Introduction}

Open any contemporary fashion magazine in the United States and you will find photographs and advertisements displaying "sun-kissed beauties" or "bronzed goddesses" portraying standards of beauty. When and why did this trend of having a sun tan become so popular? Pale skin used to mark a status symbol of wealth and beauty (Mighall, 2008). Literature referred to women as "fair maidens" and fashioned images like the iconic Disney Princesses, who possess creamy, white skin. Tan colored skin represented the lower class of manual laborers who worked outside in the sun (Righton, 2005). Sun exposure was first introduced in the early $20^{\text {th }}$ century by the medical and scientific communities for the treatment of tuberculosis and rickets; in 1903 Niels Finsen was awarded the Nobel Peace Prize in Medicine for treatment with heliotherapy. During this time, large hats, parasols, and bleaching cream were used by the upper class to avoid sun tanning and the stigma attached to tan skin (Mighall, 2008). In the Great Depression, with scarce food and low paying manual labor jobs, full figured bodies and pale skin represented the health of having plenty to eat, and the upper class wealth of not working in manual labor occupations outdoors.

Magazines like Vogue and Harpers Bazaar, and fashion icon Coco Chanel, created tan as an ideal of attractiveness in the late 1920s (Mighall, 2008). In the months of May, June, and July from the years of 1920 to 1927 in Vogue and Harpers Bazaar, there are only three pro-tan articles, and two pro-tan advertisements (Martin, et al., 2009). English Vogue in 1927 had the first tan model on the cover (Mighall, 2008). During the same months, in 1928 to 1930 , there were 30 pro-tan articles and 99 advertisements (Martin et al., 2009), showing how the media influenced tan, and a sun tan became revolutionized as healthy and attractive.

Banerjee, Campo, and Greene (2008) researched the perceived attractiveness of males and females with a tan. Re- searchers used photographs of the same models and altered their appearance to have light, medium, and dark sun tans. Males rated the female model with the dark tan as healthier and more attractive, while females did not show a significant preference for males with tans. Females reported that being attractive to men was a strong factor in their lifestyles, influencing diet choices, working out, and tanning. Females believed that sun tanning increases their physical and interpersonal attractiveness to males and sun tanning also makes them look healthier. Females often engage in the forewarned beauty risks of tanning, injections, and plastic surgery. The risks of altering aesthetic attributes are outweighed by the desire to increase their perceived attractiveness to find a mate. Males find tan females more attractive, approachable (romantically or friendly), and healthy (Benerjee et al., 2008). Other researchers have also found an attractiveness preference for tan skin (Broadstock, Borland, \& Gason, 1992; Smith, Cornelissen, \& Tovée, 2007).

The association of sun tan equaling healthy is where the paradox of sun tanning comes in. Skin cancer is now the most commonly occurring cancer in the United States (Lamanna, 2004), with more than two million people receiving treatment for basal and squamous cell skin cancer in 2006 (American Cancer Society, 2010). Researchers have also shown that despite the increase in education of skin cancer, the rate of college student sun tanning has increased in recent years (Pettijohn, Pettijohn, \& Geschke, 2009). How can the dangerous sun tanning craze be explained, since it runs counter to ideals of health and self-preservation? Past studies have shown how certain ideals of attractiveness, such as skin tone and body shape, have changed across time (Mighall, 2008). In addition, evolutionary theory (Buss, 1994; Saad \& Peng, 2006) can be used to explore why there is a preference for tan skin in mate selection.

Evolutionary psychology proposes that beauty preferences have evolved due to the indication of health and fertility factors for men, and the reproductive drive of finding a mate for women (Buss, 1994; Saad \& Peng, 2006). Skin tone is an im- 
portant signal of attractiveness because it is a visible indicator of health and fertility. Men will hunt to find youth and beauty in their mate so their offspring potentially carry these inheritable traits (Buss, 1994; Saad \& Peng, 2006). Demographically, young single women from the ages of 16 to 29 years old make up the largest faction of sun tanning patrons and dating females (Lamanna, 2004). While seeking a mate, women are more focused on the present factors that enhance their reproductive potential. On a college sun tanning inventory, $82.1 \%$ placed a high value on sun tans, and $72.8 \%$ indicated they understood the seriousness of skin cancer (Lamanna, 2004). Females had higher risk taking behaviors in sun tanning, rated the perceived risk of tanning higher, and were more knowledgeable about skin cancer than males (Lamanna, 2004). The risk behavior in sun tanning follows the life history theory that women are more likely to engage in risks if it will elevate their attractiveness level (Saad \& Peng, 2006).

With females engaging in the risk taking behavior of sun tanning to increase their chances to find a mate, they outweigh the perceived risks of skin cancer in the future for the immediate benefits of perceived health and attractiveness (Cokkinides et al., 2002; Leary \& Jones, 1993). The specific demographic group that is affected by this is the young, single dating, female population (Saad \& Peng, 2006). Females who focus on the immediate attractiveness enhancing effects of tanning disregard the predictive costs. These behavioral intentions fall in line with the Darwinian perspective of mate selection.

\section{Current Study Predictions}

Based on these previous findings, the researchers predicted females would report greater frequency of sun tanning behaviors and more positive attitudes regarding sun tanning compared to males. In addition, single students who were dating were expected to show more positive attitudes towards sun tanning and report a greater frequency of sun tanning behaviors compared to students who were in committed relationships or not dating. Married individuals were expected to show the least positive attitudes about sun tanning and report the least frequency of sun tanning behaviors. Students who are dating should place a high premium on appearance and therefore be most concerned with maintaining a perceived healthy sun tan to attract and keep a mate. Married students have already attracted a mate and established a relationship, so these individuals should be least concerned with maintaining a sun tan. Research has found that being involved in romantic relationships may protect individuals from body esteem threats and increase personal acceptance and self-beliefs (Forbes, Jobe, \& Richardson, 2006; Lin \& Kulik, 2002; Long, 1983) which may reduce the need to focus on self-enhancement behaviors, such as tanning.

\section{Method}

\section{Participants}

Three hundred fifty three ( $62.8 \%$ female) undergraduate college students from a large, public university in the state of Ohio participated in this research. The sample was $95.2 \%$ Caucasian, $1.1 \%$ Asian, 1.1\% African-American, 2\% Hispanic, and .6\% other. The average age of the sample was 21.50 years $(S D=$ 6.89 , range $=18-68$ ) and $65.6 \%$ were freshmen, $13.9 \%$ sophomores, $8.2 \%$ juniors, $8.2 \%$ seniors, and $4.0 \%$ other. The reported romantic relationship status of the students included $24.6 \%$ single non-dating, $34.6 \%$ single dating, $29.7 \%$ single committed, and $11.0 \%$ married.

\section{Materials \& Procedure}

Students enrolled in psychology courses volunteered to complete the sun tanning survey. The survey consisted of 24 sun tanning attitude questions $(\alpha=.77$; SA1-24) which were answered using a 5-point Likert scale $(1=$ strongly disagree, $2=$ disagree, $3=$ neutral, $4=$ agree, $5=$ strongly disagree $)$ and 12 sun tanning frequency questions $(\alpha=.84$; For SF1-8, $1=$ never, $2=$ once $a$ month, $3=$ once $a$ week, $4=$ two times $a$ week, $5=$ three or more times a week. For SF9-12, 1 = never, 2 = almost never, 3 = sometimes, 4 = almost always, $5=$ always). These sun tanning questions were used in a previous investigation by Pettijohn, Pettijohn, and Geschke (2009). Participants were also asked "Do you regularly engage in sun tanning behavior?" and "Do you believe individuals prefer romantic partners with sun tans?" as yes/no questions. Demographic questions were included to provide information about participant age, sex, race, year in college, and romantic relationship status.

\section{Results}

A 2 (Sex: male or female) $\times 4$ (Relationship status: single non-dating, single dating, single committed, or married) MANOVA for the sun tanning attitude questions (SA1-24) was conducted. Results revealed a significant main effect for sex, Wilks' $\lambda=0.75, F(24312)=4.32, p<.001, \eta^{2}=.25$, a significant main effect for relationship status, Wilks' $\lambda=0.75, F(72$ $933)=1.30, p=.05, \eta^{2}=.09$, and a non-significant interaction effect, Wilks' $\lambda=0.82, F(72933)=0.89, p=.71, \eta^{2}=.07$. Individual comparisons, using a Bonferroni correction, were conducted for participant sex (see Table 1). Males scored significantly higher than females on SA2, SA3, SA4, SA9, SA10, SA12, SA13, SA16, SA17, and SA19. Females scored significantly higher than males on SA5, SA20, and SA21.

One way ANOVAs were conducted to investigate the differences among relationship status for each SA question (see Table 2). Significant differences between relationship statuses were found for SA5, SA6, SA16, and SA23, while marginally significant differences were found for SA1, SA3, and SA22. Individual comparisons, using a Bonferroni correction, were also conducted for relationship status and the results are presented in Table 2.

A 2 (Sex: male or female) $\times 4$ (Relationship status: single non-dating, single dating, single committed, or married) MANOVA for the sun tanning behavior frequency questions (SF1-12) was conducted. Results revealed a significant main effect for sex, Wilks' $\lambda=0.85, F(12318)=4.76, p<.001, \eta^{2}$ $=.15$, a significant main effect for relationship status, Wilks' $\lambda=$ $0.83, F(36940)=1.76, p<.01, \eta^{2}=.06$, and a non-significant interaction effect, Wilks' $\lambda=0.91, F(36940)=0.84, p=.74$, $\eta^{2}=.03$. Individual comparisons, using a Bonferroni correction, were conducted for participant sex (see Table 3). Females scored significantly higher than males on SF1, SF3, SF5, SF7, SF10, SF11, and SF12. Males did not score significantly higher than females on any of the questions.

One way ANOVAs investigating the differences among rela- 
tionship status were also conducted for each SF question (see Table 4). Significant differences between relationship statuses were found for SF1, SF3, SF5, SF6, SF7, SF10, and SF11. Individual comparisons, using a Bonferroni correction, were also conducted for relationship status. Results are presented in Table 4.

To analyze the question "Do you regularly engage in sun tanning behavior?", two chi-square tests for independence were conducted to investigate how participant sex and relationship status were related to question responses. There was a significant relationship between participant sex and question responses, $\chi^{2}(1, N=352)=18.49, p<.001, \varphi=0.23$. Females reported regularly engaging in sun tanning behavior $(69.7 \%)$ more than males $(46.6 \%)$. There was also a significant relationship between relationship status and question responses, $\chi^{2}(3, N=353)=12.29, p<.01, \varphi=0.19$. As can be seen in Figure 1, single dating participants sun tan more regularly than other relationship status types.

To analyze the question "Do you believe individuals prefer romantic partners with sun tans?" two chi-square tests for independence were conducted to investigate how participant sex and relationship status were related to question responses.

Table 1.

Mean college student sun tanning attitude responses by sex.
There was a significant relationship between participant sex and question responses, $\chi^{2}(1, N=352)=17.39, p<.001, \varphi=$ 0.22 . Males believed individuals prefer romantic partners with sun tans $(66.4 \%)$ more than females did $(43.3 \%)$. There was also a significant relationship between relationship status and question response, $\chi^{2}(3, N=353)=19.08, p<.001, \varphi=0.23$. As can be seen in Figure 2, single dating participants believed individuals prefer romantic partners with a sun tan more than the other relationship status types.

To consider the influence of age on sun tanning attitudes and behaviors, we correlated age with SA1-24 and SF1-12. There was a significant positive correlation between age and SA20, $\mathrm{SA} 21, \mathrm{SA} 22, \mathrm{SA} 23, p \mathrm{~s}<0.05$. There was a significant negative correlation between age and SF1, SF10, and SF11, $p \mathrm{~s}<0.05$.

\section{Discussion}

Overall, the hypotheses were generally supported. With respect to sun tanning behavior, females reported significantly greater frequency of regularly sun tanning and sun tanning

\begin{tabular}{|c|c|c|}
\hline Question & Male & Female \\
\hline SA1. I look more attractive with a sun tan than without a sun tan. & $3.81(0.86)$ & $3.89(1.02)$ \\
\hline SA2. Sun tanned skin is more attractive than skin that is not sun tanned.* & $3.70(0.89)$ & $3.50(0.94)$ \\
\hline SA3. Men engage in sun tanning behavior more frequently than women.* & $3.50(0.83)$ & $3.29(0.94)$ \\
\hline SA4. Suntans look healthy.* & $3.66(0.94)$ & $3.22(0.989)$ \\
\hline SA5. I enjoy engaging in sun tanning behavior.* & $2.91(1.11)$ & $3.46(1.18)$ \\
\hline SA6. It is important for me to have a sun tan. & $2.68(1.02)$ & $2.79(1.06)$ \\
\hline SA7. Suntanned men are more attractive than men without sun tans. & $3.06(0.82)$ & $3.21(1.02)$ \\
\hline SA8. I look more attractive with a sun tan than without a sun $\tan$. & $3.69(0.92)$ & $3.78(1.05)$ \\
\hline SA9. Sun tanned individuals go out on more dates than individuals without sun tans. ${ }^{*}$ & $2.69(0.84)$ & $2.32(0.82)$ \\
\hline SA10. Sun tanned individuals have more fun than individuals without sun tans.* & $2.32(0.88)$ & $2.06(0.82)$ \\
\hline SA11. When I have a sun tan, I feel more attractive than when I do not have a sun tan. & $3.44(0.98)$ & $3.65(1.05)$ \\
\hline SA12. Men prefer to date women who have sun tans over women who do not have sun tans.* & $2.40(0.82)$ & $2.05(0.77)$ \\
\hline SA13. I look more attractive without a sun tan than with a sun $\tan { }^{*}$ & $4.24(0.78)$ & $3.92(0.82)$ \\
\hline SA14. Sun tanned individuals are healthier than individuals without sun tans. & $3.36(0.89)$ & $3.18(1.02)$ \\
\hline SA15. Women engage in sun tanning behavior more frequently than men. & $2.54(0.91)$ & $2.38(0.93)$ \\
\hline SA16. Sun tanned women are more attractive than women without sun tans.* & $2.45(0.94)$ & $2.06(0.79)$ \\
\hline SA17. Individuals who pursue sun tans are too concerned with outward appearances.* & $3.13(0.96)$ & $2.76(0.79)$ \\
\hline SA18. It is important for my boyfriend/girlfriend to have a sun tan. & $1.87(0.67)$ & $2.03(0.59)$ \\
\hline SA19. Women prefer to date men who have sun tans over men who do not have sun tans.* & $3.06(0.81)$ & $2.54(0.84)$ \\
\hline SA20. I am concerned with premature aging associated with sun tanning behavior.* & $3.26(0.93)$ & $3.64(0.94)$ \\
\hline SA21. I am concerned about getting skin cancer from exposure to UV rays.* & $3.40(1.03)$ & $3.76(0.91)$ \\
\hline SA22. Sunscreens should be used when an individual engages in sun tanning behavior. & $3.96(0.77)$ & $4.03(0.81)$ \\
\hline SA23. Sun tanning enhancers (i.e. baby oil, deep tanning lotions) should never be used. & $2.88(0.88)$ & $2.81(1.04)$ \\
\hline SA24. Being tan now is more important to me than the risk of skin cancer in the future. & $2.13(0.85)$ & $2.03(0.85)$ \\
\hline
\end{tabular}

Note. $* p<.05$. Standard deviations are presented in parentheses $(\mathrm{SD})$. For SA1-24, $1=$ strongly disagree, $2=$ disagree, $3=$ neutral, $4=$ agree, $5=$ strongly disagree 
Table 2 .

Mean college student sun tanning attitude responses by romantic relationship status.

\begin{tabular}{|c|c|c|c|c|}
\hline Question & Single Non-dating & Single Dating & Single Committed & Married \\
\hline SA1. I look more attractive with a sun tan than without a sun $\tan ^{a}{ }^{a}$ & $3.67(0.97)$ & $4.02(0.86)$ & $3.87(0.99)$ & $3.81(1.10)$ \\
\hline SA2. Sun tanned skin is more attractive than skin that is not sun tanned. & $3.45(0.95)$ & $3.68(0.93)$ & $3.52(0.86)$ & $3.66(0.99)$ \\
\hline SA3. Men engage in sun tanning behavior more frequently than women. & $3.31(0.87)$ & $3.44(0.97)$ & $3.24(0.84)$ & $3.58(0.89)$ \\
\hline SA4. Suntans look healthy. ${ }^{a}$ & $3.17(0.99)^{1}$ & $3.55(0.98)^{2}$ & $3.34(0.95)$ & $3.47(1.0)$ \\
\hline SA5. I enjoy engaging in sun tanning behavior.* & $2.91(1.21)^{1}$ & $3.42(1.12)^{2}$ & $3.40(1.14)^{2}$ & $3.16(1.29)$ \\
\hline SA6. It is important for me to have a sun tan.* & $2.59(1.08)$ & $2.95(1.02)$ & $2.67(0.98)$ & $2.71(1.18)$ \\
\hline SA7. Suntanned men are more attractive than men without sun tans. & $3.07(0.92)$ & $3.13(0.93)$ & $3.18(1.02)$ & $3.37(0.94)$ \\
\hline SA8. I look more attractive with a sun tan than without a sun $\tan$. & $3.59(1.01)$ & $3.85(0.95)$ & $3.75(0.98)$ & $3.79(1.17)$ \\
\hline SA9. Sun tanned individuals go out on more dates than individuals without sun tans. & $2.51(0.89)$ & $2.50(0.86)$ & $2.38(0.82)$ & $2.42(0.79)$ \\
\hline SA10. Sun tanned individuals have more fun than individuals without sun tans. & $2.22(0.87)$ & $2.11(0.89)$ & $2.10(0.85)$ & $2.29(0.77)$ \\
\hline SA11. When I have a sun tan, I feel more attractive than when I do not have a sun tan. & $3.40(0.99)$ & $3.64(1.02)$ & $3.67(1.00)$ & $3.53(1.16)$ \\
\hline SA12. Men prefer to date women who have sun tans over women who do not have sun tans. & $2.15(0.73)$ & $2.24(0.78)$ & $2.22(0.89)$ & $1.97(0.82)$ \\
\hline SA13. I look more attractive without a sun tan than with a sun $\tan$. & $4.10(0$. & $3.98(0.82)$ & $4.08(0$. & $3.95(0.87)$ \\
\hline SA14. Sun tanned individuals are healthier than individuals without sun tans. & $3.38(1.00)$ & $3.13(0.94)$ & $3.25(1.00)$ & $3.29(0.96)$ \\
\hline SA15. Women engage in sun tanning behavior more frequently than men. & $2.59(0.94)^{1}$ & $2.39(0.95)$ & $2.49(0.89)$ & $2.08(0.85)^{2}$ \\
\hline SA16. Sun tanned women are more attractive than women without sun tans.* & $2.23(.89)$ & $2.38(.89)^{1}$ & $1.99(.83)^{2}$ & $2.16(0.75)$ \\
\hline SA17. Individuals who pursue sun tans are too concerned with outward appearances. & $2.87(0.93)$ & $2.92(0.91)$ & $2.92(0.82)$ & $2.79(0.78)$ \\
\hline SA18. It is important for my boyfriend/girlfriend to have a sun $\tan$. & $2.01(0.66)$ & $1.99(0.62)$ & $1.92(0.61)$ & $1.95(0.57)$ \\
\hline SA19. Women prefer to date men who have sun tans over men who do not have sun tans. & $2.83(0.88)$ & $2.78(0.80)$ & $2.68(0.91)$ & $2.53(0.86)$ \\
\hline SA20. I am concerned with premature aging associated with sun tanning behavior. & $3.50(0.94)$ & $3.47(0.95)$ & $3.39(0.95)^{1}$ & $3.87(0.91)^{2}$ \\
\hline SA21. I am concerned about getting skin cancer from exposure to UV rays. & $3.64(0.93)$ & $3.60(0.99)$ & $3.58(1.02)$ & $3.82(0.87)$ \\
\hline SA22. Sunscreens should be used when an individual engages in sun tanning behavior. ${ }^{a}$ & $4.15(0.81)$ & $3.88(0.84)^{1}$ & $3.91(0.73)^{1}$ & $4.32(0.66)^{2}$ \\
\hline SA23. Sun tanning enhancers (i.e. baby oil, deep tanning lotions) should never be used.* & $2.99(0.98)$ & $2.68(0.94)^{1}$ & $2.77(0.97)$ & $3.13(1.10)^{2}$ \\
\hline SA24. Being tan now is more important to me than the risk of skin cancer in the & $2.06(0.80)$ & $2.16(0.89)$ & $2.00(0.80)$ & $1.97(0.94)$ \\
\hline
\end{tabular}

Note. ${ }^{a} p<.10, * p<.05$. Standard deviations are presented in parentheses (SD). Significant individual comparison results are denoted by non-matching numbers within category rows, $p<.05$. For SA1-24, $1=$ strongly disagree, $2=$ disagree, $3=$ neutral, $4=$ agree, $5=$ strongly disagree.

Table 3.

Mean college student sun tanning behavior responses by sex.

\begin{tabular}{lcc}
\hline \multicolumn{1}{c}{ Question } & Male & Female \\
\hline SF1. In the winter, how often do you engage in sun tanning behavior indoors (e.g. tanning bed or lamp)?* & $1.37(0.93)$ & $1.90(1.28)$ \\
SF2. In the winter, how often do you engage in sun tanning behavior outdoors? & $1.21(0.77)$ & $1.15(0.58)$ \\
SF3. In the spring, how often do you engage in sun tanning behavior indoors (e.g. tanning bed or lamp)?* & $1.39(1.00)$ & $2.29(1.50)$ \\
SF4. In the spring, how often do you engage in sun tanning behavior outdoors? & $2.10(1.33)$ & $2.03(1.22)$ \\
SF5. In the summer, how often do you engage in sun tanning behavior indoors (e.g. tanning bed or lamp)?* & $1.28(0.80)$ & $1.64(1.16)$ \\
SF6. In the summer, how often do you engage in sun tanning behavior outdoors? & $3.01(1.61)$ & $3.52(1.36)$ \\
SF7. In the autumn, how often do you engage in sun tanning behavior indoors (e.g. tanning bed or lamp)?* & $1.31(.85)$ & $1.81(1.22)$ \\
SF8. In the autumn, how often do you engage in sun tanning behavior outdoors? & $1.89(1.29)$ & $1.63(1.07)$ \\
SF9. How often do you use sunscreen when engaging in sun tanning behavior? & $1.83(1.18)$ & $2.05(1.33)$ \\
SF10. How often do you use sun tanning enhancers (i.e. baby oil, deep tanning lotions) when engaging in sun tanning behavior?* & $1.71(1.17)$ & $2.43(1.42)$ \\
SF11. How often do you engage in sun tanning behavior for special events (e.g. weddings, dances, social events)?* & $1.96(1.24)$ & $2.98(1.32)$ \\
SF12. How often do you use artificial sun tan products (i.e. lotions, sprays, or pills)?* & $1.25(0.65)$ & $1.78(1.06)$ \\
\hline
\end{tabular}

Note. $* p<.05$. Standard deviations are presented in parentheses (SD). For SF1-8, $1=$ never, $2=$ once a month, $3=$ once a week, $4=$ two times a week, $5=$ three or more times $a$ week. For SF9-12, 1 = never, 2 =almost never, 3 = sometimes, 4 = almost always, $5=$ always. 
Table 4.

Mean college student sun tanning behavior responses by romantic relationship status.

\begin{tabular}{|c|c|c|c|c|}
\hline Question & Single Non-dating & Single Dating & Single Committed & Married \\
\hline $\begin{array}{l}\text { SF1. In the winter, how often do you engage in sun tanning behavior indoors } \\
\text { (e.g. tanning bed or lamp)?* }\end{array}$ & $1.30(0.66)^{1}$ & $1.95(1.32)^{2}$ & $1.91(1.35)^{2}$ & $1.30(0.85)^{1}$ \\
\hline SF2. In the winter, how often do you engage in sun tanning behavior outdoors?* & $1.05(0.27)^{1}$ & $1.20(0.66)$ & $1.16(0.66)$ & $1.43(1.07)^{2}$ \\
\hline $\begin{array}{l}\text { SF3. In the spring, how often do you engage in sun tanning behavior indoors } \\
\text { (e.g. tanning bed or lamp)?* }\end{array}$ & $1.40(0.98)^{1}$ & $2.26(1.50)^{2}$ & $2.16(1.49)^{2}$ & $1.76(1.38)$ \\
\hline SF4. In the spring, how often do you engage in sun tanning behavior outdoors? & $1.92(1.25)$ & $1.99(1.23)$ & $2.23(1.27)$ & $2.11(1.31)$ \\
\hline $\begin{array}{l}\text { SF5. In the summer, how often do you engage in sun tanning behavior indoors } \\
\text { (e.g. tanning bed or lamp)?* }\end{array}$ & $1.23(0.70)^{1}$ & $1.70(1.23)^{2}$ & $1.57(1.12)$ & $1.38(0.86)$ \\
\hline SF6. In the summer, how often do you engage in sun tanning behavior outdoors?* & $2.82(1.54)^{1}$ & $3.42(1.49)^{2}$ & $3.61(1.33)^{2}$ & $3.43(1.39)$ \\
\hline $\begin{array}{l}\text { SF7. In the autumn, how often do you engage in sun tanning behavior indoors } \\
\text { (e.g. tanning bed or lamp)?* }\end{array}$ & $1.33(0.78)^{1}$ & $1.78(1.22)^{2}$ & $1.80(1$. & $1.35(0.89)$ \\
\hline SF8. In the autumn, how often do you engage in sun tanning behavior outdoors? & $1.59(1.08)$ & $1.80(1.22)$ & $1.77(1.20)$ & $1.65(1.03)$ \\
\hline SF9. How often do you use sunscreen when engaging in sun tanning behavior? & $1.93(1.31)$ & $1.85(1.14)$ & $2.10(1.38)$ & $2.08(1.34)$ \\
\hline $\begin{array}{l}\text { SF } 10 . \text { How often do you use sun tanning enhancers (i.e. baby oil, deep tanning lotions) } \\
\text { when engaging in sun tanning behavior?* }\end{array}$ & $1.83(1.21)^{1}$ & $2.47(1.44)^{2}$ & $2.31(1.44)^{2}$ & $1.54(.96)^{1}$ \\
\hline $\begin{array}{l}\text { SF11. How often do you engage in sun tanning behavior for special events } \\
\text { (e.g. weddings, dances, social events)?* }\end{array}$ & $2.08(1.29)^{1}$ & $2.79(1.37)^{2}$ & $2.93(1.38)^{2}$ & $2.32(1.25)$ \\
\hline SF12. How often do you use artificial sun tan products (i.e. lotions, sprays, or pills)? & $1.55(0.89)$ & $1.57(0.95)$ & $1.57(1.00)$ & $1.76(1.09)$ \\
\hline
\end{tabular}

Note. $* p<.05$. Standard deviations are presented in parentheses (SD). Significant individual comparison results are denoted by non-matching numbers within category rows, $p<.05$. For SF1-8, $1=$ never, $2=$ once $a$ month, $3=$ once $a$ week, $4=$ two times $a$ week, $5=$ three or more times $a$ week. For SF9-12, $1=$ never, $2=$ almost never, $3=$ sometimes, $4=$ almost always, $5=$ always.

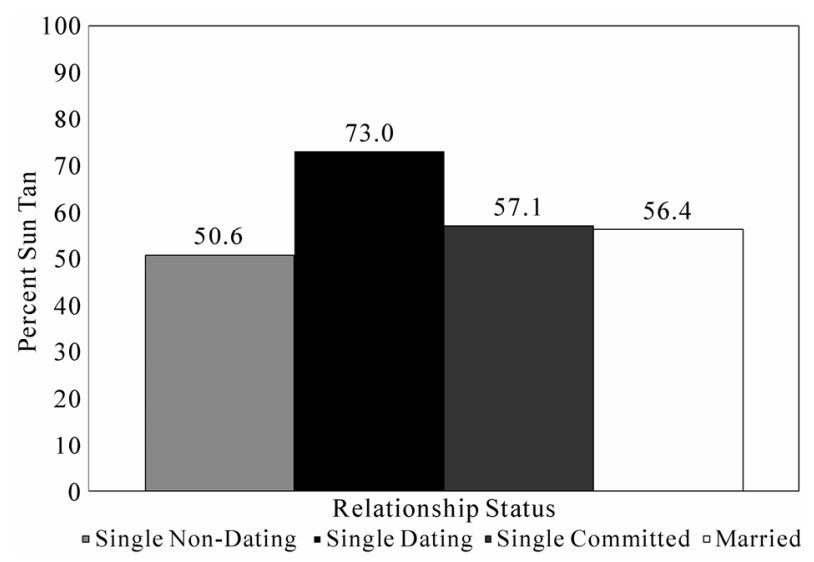

Figure 1.

Percentage of respondents who regularly sun tan by relationship status.

indoors during all seasons compared to males. Females also reported a higher frequency of using sun tanning enhancers, tanning for special events, and using artificial tanning products than their male counterparts. We were surprised to see similar reported sun tanning behaviors between men and women outdoors. While few individuals reported sun tanning outdoors in the winter, fall, and spring, females reported tanning more often than males in the summer, but this difference was not statistically significant. There were also no significant differences in sunscreen use between men and women in our sample. Older individuals reported tanning less often indoors in the winter, using sun tanning enhancers, and tanning for special events.

While considering relationship status, the pattern of results for sun tanning behaviors were more varied, despite a general

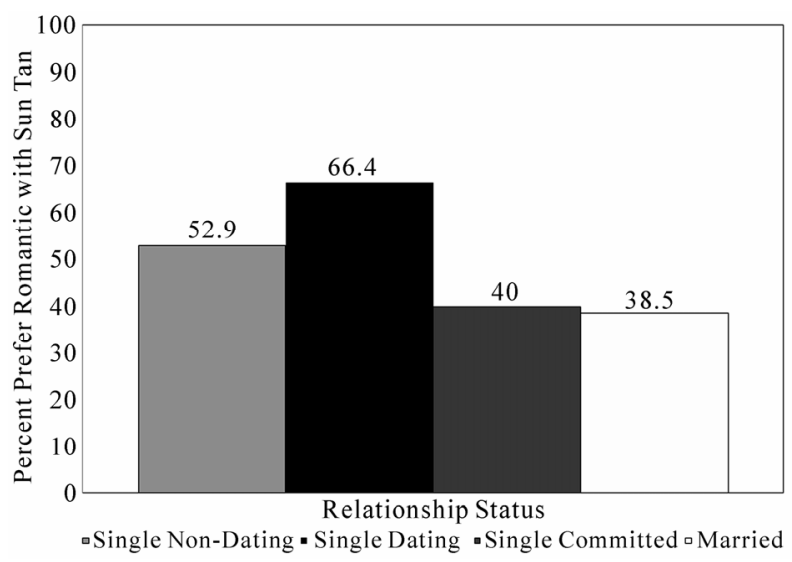

Figure 2.

Percentage of respondents who believe individuals prefer romantic partners with sun tans by relationship status.

trend consistent with predictions for single dating individuals to sun tan most frequently and married or single non-dating individuals to sun tan least frequently. Single dating individuals also reported using sun tan enhancers most often, while married individuals reported using sun tan enhancers least often. Single non-dating individuals were more similar to married individuals in their sun tanning behavior, which may be related to their non-participation in dating. If dating is not important, individuals do not need to engage in behaviors (i.e., sun tanning) to enhance their appearance to attract a potential mate. Individuals in dating relationships may also be more concerned and unhappy with body satisfaction compared to individuals in committed relationships or individuals not dating (Forbes, Jobe, \& 
Richardson, 2006; Lin \& Kulik, 2002; Long, 1983). Brandberg, Ullen, Sjoberg, and Holm (1998) found that females with lower body satisfaction sun tanned more than females with higher body satisfaction and Leary and Jones (1993) found that those interested in making a favorable appearance impression were most likely to sun tan.

The sun tanning attitudes results were somewhat mixed overall. While females reported more positive attitudes regarding the experience of sun tanning compared to males, they were also more concerned with skin cancer and premature aging. Males reported more positive attitudes related to the enhanced appearance of sun tanned individuals over individuals without a sun tan. Men's beliefs that sun tans are healthy, attractive, and desirable in mates is consistent with previous research demonstrating these preferences (e.g., Benerjee et al., 2008). While males may not go out of their way to engage in purposeful sun tanning behavior, or enjoy the sun tanning experience, they do recognize the importance of a sun tan in mate attraction.

With the variable of relationship status, the pattern of results for sun tanning attitudes is also varied, despite a general trend consistent with predictions for single dating individuals to hold more positive sun tanning attitudes and married or single non-dating individuals to hold less positive sun tanning attitudes. For example, single dating individuals reported the greatest preferences for romantic partners with sun tans, thought they themselves look more attractive with a sun tan, thought tans look healthy, and believed it is important to have a sun tan, whereas married and single non-dating individuals reported the least agreement with these statements. Single dating individuals were the least likely to agree that sun tanning enhancers should never be used and sunscreens should be used when sun tanning, while single non-dating and married individuals were more likely to support these attitude statements. Older individuals reported more concern about premature aging and getting skin cancer from tanning as well as a negative attitude about the use of sun tanning enhancers.

We would like to draw attention to some of the limitations of the current investigation. We acknowledge that we only assessed reported behaviors and attitudes of college students and that actual behavior may not directly correspond with these responses (Ajzen \& Fishbein, 1977). Special circumstances, social desirability, peer pressure, and social norms may influence sun tanning behaviors in real world settings (Stapleton, Turrisi, \& Hillhouse, 2008). Additional observations of sun tanning frequencies, sunscreen purchases, and other tanning behaviors would be a welcome addition to the current results. It should also be noted that partners in a relationship may provide a strong motivation for reducing risky sun tanning activities, such as sunscreen use (Mosher \& Danoff-Burg, 2008).

Furthermore, our sample consisted of college students from the Midwest section of the United States. While college is an ideal setting to explore romantic relationships and their influences on other variables due to the large number of similar individuals in close proximity, we cannot extend our results to non-college populations or areas outside the Midwest. It would be interesting to assess sun tanning attitudes and behaviors from a wide range of ages and geographic locations to provide further clarification of results. Alternative measures with demonstrated reliability and validity may also be used to accurately measure specific dimensions of sun tanning attitudes and planned behaviors (e.g., Cafri et al., 2008). In addition, our sample was almost exclusively heterosexual, but the sun tanning attitudes and behavior of varying sexual orientations would be interesting to explore in the future (Reilly \& Rudd, 2008).

Understanding sex differences and the effect of relationship status on sun tanning attitudes and behaviors is important in determining individuals most at risk for skin cancer. Specifically, the current research indicates females, and individuals who are dating, are especially at risk for health related consequences of sun tanning. Since sun tans are so valued among these groups, future research regarding methods to reduce these unhealthy attitudes and preferences are recommended.

\section{Acknowledgements}

The authors thank Kimberly LaPiene, Lauren Dickey, and Arsida Ndoni for helpful comments on an earlier draft of this manuscript.

\section{References}

Ajzen, I., \& Fishbein, M. (1977). Attitude-behavior relations: A theoretical analysis and review of empirical research. Psychological Bulletin, 84, 888-918. doi:10.1037/0033-2909.84.5.888

American Cancer Society (2010). Cancer facts and figures. Atlanta, GA: American Cancer Society.

Banerjee, S., Campo, S., \& Greene, K. (2008). Fact or wishful thinking? Biased expectations in 'I think I look better when I'm tanned. American Journal of Health Behavior, 32, 243-252.

Brandberg, Y., Ullen, H., Sjoberg, L., \& Holm, L. E. (1998). Sunbathing and sunbed use related to self-image in a randomized sample of Swedish adolescents. European Journal of Cancer Prevention, 7 321-329. doi:10.1097/00008469-199808000-00008

Broadstock, M., Borland, R., \& Gason, R. (1992). Effects of suntan on judgements of healthiness and attractiveness by adolescents. Journal of Applied Social Psychology, 22, 157-172. doi:10.1111/j.1559-1816.1992.tb01527.x

Buss, D. M. (1994). The evolution of desire: Strategies of human mating. New York: Basic Books.

Cafri, G., Thompson, J. K., Roehrig, M., Rojas, A., Sperry, S., Jacobsen, P. B., \& Hillhouse, J. (2008). Appearance motives to tan and not tan: Evidence for validity and reliability of a new scale. Annals of Behavioral Medicine, 35, 209-220. doi:10.1007/s12160-008-9022-2

Cokkinides, V. E., Weinstock, M. A., O’Connell, M. C., \& Thun, M. J. (2002). Use of indoor tanning sunlamps by US youth, ages 11-18 years, and by their parent or guardian caregivers: Prevalence and correlates. Pediatrics, 109, 1124-1130. doi:10.1542/peds.109.6.1124

Forbes, G., Jobe, R., \& Richardson, R. (2006). Associations between having a boyfriend and the body satisfaction and self-esteem of college women: An extension of the Lin and Kulik hypothesis. Journal of Social Psychology, 146, 381-384. doi:10.3200/SOCP.146.3.381-384

Lamanna, L. M. (2004). College students' knowledge and attitudes about cancer and perceived risks of developing skin cancer. Dermatology Nursing, 16, 161-167.

Leary, M. R., \& Jones, J. L. (1993). The social psychology of tanning and sunscreen use: Self-presentational motives as a predictor of health risk. Journal of Applied Social Psychology, 23, 1390-1406. doi:10.1111/j.1559-1816.1993.tb01039.x

Lin, L. F., \& Kulik, J. A. (2002). Social comparison and women's body satisfaction. Basic and Applied Social Psychology, 24, 115-123.

Long, B. (1983). A steady boy friend: A step toward resolution of the intimacy crisis for American college women. Journal of Psychology: Interdisciplinary and Applied, 115, 275-280. 
doi:10.1080/00223980.1983.9915445

Martin, J., Ghaferi, J., Cummins, D., Mamelak, A., Schmults, C., Parikh, M., \& Liégeois, N. J. (2009). Changes in skin tanning attitudes: Fashion articles and advertisements in the early 20th century. American Journal of Public Health, 99, 2140-2146. doi:10.2105/AJPH.2008.144352

Mighall, R. (2008). I should Coco: As you prepare to 'cover up' on the beach this summer, lie back and enjoy Robert Mighall's true history of sunbathing. History Today, 58, 31-33.

Mosher, C. E., \& Danoff-Burg, S. (2008). Social predictors of sunscreen and self-tanning product use. Journal of American College Health, 54, 166-168. doi:10.3200/JACH.54.3.166-168

Pettijohn, T. F. II, Pettijohn, T. F., \& Geschke, K. S. (2009). Changes in sun tanning attitudes and behaviors of U.S. college students from 1995 to 2005. College Student Journal, 43, 161-165.
Reilly, A., \& Rudd, N. A. (2008). Sun, salon, and cosmetic tanning Predictors and motives. International Journal of Human and Social Sciences, 2, 170-176.

Righton, B. (2005). Glow from a bottle. Maclean's, 18, 40-41.

Saad, G., \& Peng, A. (2006). Applying Darwinian principles in designing effective intervention strategies: The case of sun tanning. Psychology \& Marketing, 23, 617-638. doi:10.1002/mar.20149

Smith, K., Cornelissen, P., \& Tovée, M. (2007). Color 3D bodies and judgements of human female attractiveness. Evolution and Human Behavior, 28, 48-54. doi:10.1016/j.evolhumbehav.2006.05.007

Stapleton, J., Turrisi, R., \& Hillhouse, J. (2008). Peer crowd identification and indoor artificial UV tanning behavioral tendencies. Journal of Health Psychology, 13, 940-945. doi: $10.1177 / 1359105308095068$ 